\title{
Developing the Linking Climate Adaptation Network: Progress and Prospects
}

\author{
Farhana Yamin, Saleemul Huq and Atiq Rahman
}

\section{Introduction}

This article provides a brief overview of the rationale, functioning and future plans of the Linking Climate Adaptation Network which was one of the final components of the DFID-funded Linking Climate Adaptation (LCA) Project. The objective of the Project is set out in the overview article (Yamin, Rahman and Huq, this IDS Bulletin). To understand how policy and institutional processes could support communityled adaptation, the LCA Project Team undertook case studies of adaptation in six countries which are set out in this IDS Bulletin together with a synthesis of key findings.

An additional, longer term way to make policy and institutional processes more responsive was through the creation of the LCA Network by the LCA Project Team. The core objective for the Network was to assist communities and adaptation experts to share theoretical, policy and experiential knowledge to support community-led adaptation in developing countries. For many reasons, communities are not well connected to formal scientific and policy processes. Knowledge system approaches that analyse how knowledge and information is generated, shared, negotiated and transformed into policy partly explain why the knowledge, preferences and perspectives of the poor are not fully taken into account. Allowing geographically dispersed communities with fewer resources to communicate better "upwards" with those engaged in formal scientific and policy responses was thus considered an important objective of the LCA Project.

This article sets out how this objective was achieved through the LCA Network by explaining the rationale for the Network, its current operation and plans for its further elaboration.

\section{Rationale for the LCA Network}

Discussion within the LCA Project Team and with others involved in adaptation emphasised the need for an independent, on-going mechanism of communication and networking. This was needed to supplement more episodic means of community engagement such as UN Framework Convention on Climate Change (UNFCCC) side-events (limited to those few with resources to travel) or stakeholder workshops relating to specific projects or policy consultations (which benefit from broader representation but are time-bound and may be externally driven). An independent, ongoing communication mechanism would better match the needs of communities as well as of the climate regime. This is because climate change is a longterm global issue with an iterative policy cycle that encompasses all levels of governance.

Additionally, given its high political profile and its relative "youth" as an international issue, developments in climate science and policy happen too swiftly for communities to keep up with. These considerations call for long-term relationships among a wide range of actors active at the grassroots, epistemic and policy-making levels. Such relationships must be established on the basis of trust and be able to function across geographical, political and institutional boundaries. Experience from the field of participatory methodologies suggested that early experiences of shared understandings of issues and concepts could advance intellectual coherence of differing approaches and foster a degree of coordination among and across the climate change, development and disaster risk reduction domains. These considerations were important because early parts

IDS Bulletin Vol 36 No 4 October 2005 ( Institute of Development Studies 
of the research under the LCA Project demonstrated a high level of conceptual confusion about adaptation-related work in the climate change, development and disasters field. The creation of a Network providing virtual and face-to-face opportunities for a wide group of individuals and institutions to learn about related work in other policy realms was considered a useful way to advance the climate adaptation agenda.

The LCA Team considered the target groups for the Network to be found in the following three, currently largely disconnected, policy domains: (a) the climate change regime, (b) development activities related to poverty reduction and Millennium Development Goals (MDGs), such as Poverty Reduction Strategy Papers (PRSPs), country strategy papers prepared for various donors and the work of the Organisation for Economic Cooperation and Development's Development Assistance Committee (OECD DAC), and (c) disaster risk reduction (DRR) activities.

A phased approach was agreed given the timescales and resources available to the LCA Team. For Phase I (2004-5), the key issue was to gauge interest in the concept of a Network, to identify members and to get the Network up and running - even in a "bare bones" manner among those most interested. It was agreed that Phase I should focus on inviting people to join the Network in their individual capacity to avoid institutional "turf" issues. Identification of individuals would be through the knowledge of the LCA Team, enhanced with "snowballing" techniques where those in the know are asked to invite others they know to join the Network. Initial contacts would be derived from attendees at various international meetings relating to climate change, adaptation and disaster relief.

It was agreed that the longer term scoping of what role the Network might play, who should do what and related funding needs, should be done in late 2005 after the LCA Project has ended (Phase II). This second should also prioritise the resourceintensive task of identifying those not yet active but who may be interested, and also of establishing possible tiers of Network membership.

Finally, in terms of the long-term vision for the Network, LCA Team members considered different networks' experience with which they were familiar, or suggested by others, that might usefully guide the development of the LCA Network. These include:
- Participatory Learning and Action (formerly PLA Notes and Rapid Rural Appraisal (RRA) Notes) and the Resource Centers for Participatory Learning and Action (RCPLA) Network

- Comparing and supporting endogenous development and biocultural diversity

- Centre for Information on Low External Input and Sustainable Agriculture (ILEIA)

- International Centre for Tropical Agriculture (CIAT) innovation histories

\section{Current operation of the LCA Network}

Phase I of the Network has resulted in the establishment of a dedicated website, an email listserve, and exchange of literature and materials by members. This Network currently has 471 subscribers from across the globe (with around 450 actual members due to individuals subscribing with multiple emails). Membership is increasing, mostly by word of mouth (snowballing), since the initial set-up in March 2005.

Most of the email exchanges thus far have been information about recent publications, and forthcoming conferences, as well as ongoing consultations and projects. Discursive exchanges have been more limited, reflecting the fact that the Network is somewhat new and unfamiliar - not everyone knows each other on a personal level and people are very busy and uncertain about what is/not appropriate to contribute.

\section{Development of the LCA Network}

Informally, many LCA Network members have expressed a desire for more focused discussions on upcoming issues relating to the climate change agenda items and discussions to clarify fundamental concepts. There is strong support for seeing how the Network can operate as a resource centre to provide information on who is doing what as well as on funding and sources of expertise in developed and developing countries. It is likely that if an initial "chunk" of information could be provided centrally, it would prompt others to contribute on an ongoing basis. Each of these activities would, in different ways, support climate adaptation advocacy and implementation by communities. But this would require resources for the LCA Network that are beyond those currently available.

If these were available, the Network could comprise a number of outputs and activities to 
support community-led adaptation through the following:

- Publication of a LCA newsletter

- Opinion pages and discussion forum(s)

- New literature bibliographies and documents (including old relevant literature) broken down by region, sector and country to aid developing country scholarship

- Events calendar

- Resource manuals and guides (e.g. on participatory methodologies) including Network members' news/reviews of these from the field

- Project news broken down by region, sector, county

- Key organisations and their climate adaptation relevant activities

- Major funding initiatives (conventions, international financial institutions (IFIs), regional banks, bilateral programmes, foundations and private sources)

- Network "who's who" page with pictures and contacts

- Ensuring opportunities for the whole Network to come together in a "trade fair" or social summit-type setting every 18-24 months to encourage face-to-face communication among practitioners, policy makers, activists and NGOs.

\section{Next steps}

Unless proper thought is given to how the Network will function in a sustainable fashion over the long term, funding and others discordant issues may arise leading to frustrations and suboptimal use. Based on experience of other networks, considerations that need further elaboration include:

- secure access to those without web facilities;

- involving non-English language participants;

- avoiding dominance of print;

- clarifying core functions and responsibilities for developing countries to avoid entrenching current knowledge/power imbalances;

- quality control, copyright and editorial control issues;

- fundraising roles and responsibilities; and

- governance structures to secure "buy in", transparency and accountability.

Consideration of these issues will continue within the LCA Project Team and others interested in taking the idea of the Network forward at the eleventh Conference of the Parties in Montreal in December 2005. The authors of this article warmly invite those interested in contributing to discussions about the Network's future to join the Network or to contact us at any time.

For more information about the Network and how to join, visit the IDS Climate Change website at http://community.eldis.org/lca/ or to join send an email to lca@lyris.ids.ac.uk. An archive of previous messages can be found at http://community. eldis.org/lca 